\title{
Dose response study of ipratropium bromide aerosol on maximum exercise performance in stable patients with chronic obstructive pulmonary disease
}

\author{
Akihiko Ikeda, Koichi Nishimura, Hiroshi Koyama, Mitsuhiro Tsukino, Michiaki \\ Mishima, Takateru Izumi
}

\begin{abstract}
Background - Although the bronchodilating effect of inhaled anticholinergics has been established in patients with chronic obstructive pulmonary disease (COPD), their effects on exercise capacity are still controversial. Previous studies have suggested that the standard dosage hardly affects exercise tolerance, whereas higher doses might elicit an improvement. The aim of the present study was to determine the dose of ipratropium bromide aerosol that improves exercise performance using progressive cycle ergo-
\end{abstract} metry in patients with stable COPD.

Methods - Twenty men with stable COPD of mean (SD) age $69.2(4.6)$ years and forced expiratory volume in one second $\left(\mathrm{FEV}_{1}\right) \mathbf{1 . 0 0}(0.37) 1$ were studied in a randomised double blind manner. Each patient received ipratropium bromide in doses of $240 \mu \mathrm{g}, 160 \mu \mathrm{g}, 80 \mu \mathrm{g}, 40 \mu \mathrm{g}$, and placebo from a metered dose inhaler (MDI) with an InspirEase spacer on five separate days. Spirometric parameters were assessed before and at $30,60,90$, and 120 minutes after each inhalation, and pulse rate and blood pressure were also measured immediately before each spirometric measurement. Symptom limited progressive (20 watts/min) cycle ergometer exercise tests were performed 90 minutes after each inhalation.

Results - Ipratropium bromide in doses of $160 \mu \mathrm{g}$ and $240 \mu \mathrm{g}$ produced a greater increase in $\mathrm{FEV}_{1}$ than $40 \mu \mathrm{g}$ or $80 \mu \mathrm{g}$ ipratropium bromide at all time points. Doses of $160 \mu \mathrm{g}$ and $240 \mu \mathrm{g}$ ipratropium bromide also produced greater increases in maximal work load and maximal oxygen consumption than placebo, whereas $40 \mu \mathrm{g}$ and $80 \mu \mathrm{g}$ ipratropium bromide did not. There was a weak correlation between the change in $\mathrm{FEV}_{1}$ and the change in maximal work load $(r=0 \cdot 45)$. No differences were found in pulse rate or blood pressure between the treatment and placebo groups, and no side effects were noted throughout the study.

Conclusions - A dose of at least four times the standard dose of ipratropium bromide from an MDI with a spacer device was necessary to improve maximal cycle exercise capacity in patients with stable
COPD. Although the data from cycle ergometry cannot be directly applied to exercise performed during day to day activities, it is conceivable that the recommended doses of ipratropium bromide do not elicit the optimal clinical benefits.

(Thorax 1996;51:48-53)

Keywords: chronic obstructive pulmonary disease (COPD), ipratropium bromide, exercise capacity.

The goal of treatment of chronic obstructive pulmonary disease (COPD) with bronchodilators is to improve airways obstruction and to improve exercise tolerance. While the dilating effect of inhaled bronchodilators in patients with COPD has been established, ${ }^{1-5}$ their effects on exercise capacity are still controversial. To date, several studies have examined the relationship between short term bronchodilator response and exercise capacity, ${ }^{6-10}$ but only a few studies have shown that exercise capacity, assessed using cycle ergometry, is improved by an inhaled anticholinergic agent. In each study only a single small dose of an inhaled anticholinergic was evaluated, and the results suggested that the standard dosage hardly affects exercise tolerance whereas higher doses might elicit an improvement.

The purpose of the present study was to determine the dose of ipratropium bromide that produces the maximum improvement in exercise performance, evaluated by progressive cycle ergometry, and also to determine if there is a significant relationship between this improvement in airways obstruction and exercise capacity in patients with COPD.

\section{Methods}

PATIENTS

Twenty men with clinically stable COPD ${ }^{11}$ were recruited from about 200 patients attending the outpatient clinic at the Chest Disease Research Institute, Kyoto University. Entry criteria included age over 55 years, a smoking history, chest radiographs showing hyperinflation, a forced expiratory volume in one second $\left(\mathrm{FEV}_{1}\right)$ of less than $80 \%$ of the predicted value, a best post-bronchodilator $\mathrm{FEV}_{1}$ /forced vital capacity (FVC) of less than 0.7 , and the absence of other disorders likely to affect exercise. Those 
with an exacerbation of their pulmonary disease within the last three months, a history of asthma, severe hypoxaemia $\left(\mathrm{PaO}_{2}\right.$ less than 8 $\mathrm{kPa}$ at rest), or treatment with oral bronchodilators, including theophylline, were excluded. None of the patients had taken oral or inhaled corticosteroids in the preceding three months. All were ex-smokers. In order to familiarise the patients with the testing technique and to confirm that their exercise tolerance was limited by mechanical ventilatory capacity, each subject underwent progressive exercise studies on at least two occasions before entering the trial. Written informed consent was obtained prior to the initiation of the study. The study protocol was approved by the ethics committee of our institute.

\section{PULMONARY FUNCTION TESTS}

Spirometric tests were performed using the methods described in the American Thoracic Society 1987 update. ${ }^{12}$ Three consecutive flow volume curves were recorded with a spirometer (Autospiro AS-600, Minato Medical Science Co Ltd, Osaka, Japan) which was calibrated with a three litre syringe before each day of testing. The highest $\mathrm{FEV}_{1}$ and FVC from triplicate measurements were analysed.

Baseline pulmonary function tests were performed within the three months preceding the study and at least 12 hours after the administration of bronchodilators had been suspended. In addition to usual spirometric testing (Chestac-65, Chest, Tokyo), maximum voluntary ventilation (MVV) was performed with the patient breathing maximally into a pneumotachograph for 12 seconds, and then multiplied to obtain a per minute value. Functional residual capacity (FRC) was measured by body plethysmography (MBR-600, Nihon Kohden Co, Tokyo, Japan), and residual volume (RV) was calculated as the FRC minus the expiratory reserve volume measured by spirometric testing. Total lung capacity (TLC) was determined as the sum of the vital capacity and RV. Static compliance (Cst) and airways resistance (Raw) were also measured by plethysmography. The transfer factor of the lung for carbon monoxide (TLCO) was measured by the single breath technique (Chestac-65, Chest, Tokyo). The predicted values for the pulmonary function indices were those given by the Japan Society of Chest Diseases. ${ }^{13}$

\section{PROGRESSIVE EXERCISE TESTS}

An electrically braked cycle ergometer (Corival WLP-400, Lode, Groningen, The Netherlands) was used to increase the exercise workload progressively. After unloaded pedalling for three minutes, the workload was increased automatically at increments of one watt every three seconds to the limit of tolerance. Patients maintained a pedalling frequency above 40 cycles per minute throughout the test. A face mask connected to a low resistance unidirectional valve (Rudolph Face Mask Exercise Testing, Hans Rudolph Inc, Kansas City,USA) was placed on the patient's face without leak- age. Exercise data were recorded using an automated exercise testing system (Desktop Diagnostics/CPX, Medical Graphic Corporation, St Paul, USA) which converts breathby-breath analog input to digital form in an on-line fashion. The testing system included a pneumotachograph with a gas analyser module and a personal computer interfaced to the measuring instrument. Minute ventilation (VE) and oxygen and carbon dioxide tensions in the expired air were determined every eight breaths, and from these measurements the mean $\mathrm{VE}$, oxygen uptake $\left(\dot{\mathrm{VO}}_{2}\right)$, and carbon dioxide production $\left(\mathrm{V} \mathrm{CO}_{2}\right)$ were rapidly calculated. Routine volume calibration was accomplished with a three litre syringe. A gas analyser was calibrated just before the study with air and a standard reference gas mixture ( $15 \%$ oxygen, $5 \%$ carbon dioxide). Arterial oxygen saturation $\left(\mathrm{SaO}_{2}\right)$ was measured by pulse oximetry (N-200 pulse oximeter, Nellcor Inc, Hayward, USA), and heart rate (HR) and waveform were measured by electrocardiography (Life Scope 8, Nihon Koden Co, Tokyo, Japan). At the end of each exercise test symptoms of leg effort and breathlessness were scored with the Borg scale (0 to 10 ), which was presented within easy vision of the subject. None of the tests was terminated by the attending physician because of untoward clinical signs or electrocardiographic changes suggestive of significant myocardial ischaemia. Analysis of the expired gas and monitoring of $\mathrm{SaO}_{2}$ and $\mathrm{HR}$ continued for three minutes after stopping the exercise. Maximal work rate (Wmax) was defined as the highest work level that was reached. Similarly, maximal $\mathrm{HR}, \dot{\mathrm{Vo}}_{2}$ $\left(\dot{\mathrm{V}}_{2} \mathrm{max}\right)$, and $\mathrm{VE}(\mathrm{VEmax})$ were the end point levels reached during the exercise. All the exercise tests were performed by the same doctor (HK) who was blinded to the results of the spirometric tests.

\section{STUDY DESIGN}

The present study, conducted between September 1992 and October 1993, was performed in a randomised, double blind, placebo controlled crossover fashion at about the same time on five separate days within a two week period (the interval between testing ranged from two to four days). The patients were requested to stop taking inhaled bronchodilators for at least 12 hours before entering the study.

All of the patients received ipratropium bromide $(20 \mu \mathrm{g} / \mathrm{puff})$ in doses of $240 \mu \mathrm{g}$, $160 \mu \mathrm{g}, 80 \mu \mathrm{g}, 40 \mu \mathrm{g}$, and placebo from a metered dose inhaler (MDI) with a spacer device, InspirEase (Schering-Plough, Japan). ${ }^{14}$ The drug doses were given in random order. The spacer attached MDI was held in the mouth and, after the patient had exhaled to functional residual capacity, the canister was activated. Patients inhaled very slowly until total lung capacity was reached, and then the breath was held for at least ten seconds. To ensure that the drugs were administered always in the same way, the inhalation technique was carefully observed by the same doctor (AI) who 
Table 1 Clinical data of the 20 patients entered in the study

\begin{tabular}{|c|c|c|}
\hline & Mean $(S D)$ & Range \\
\hline Age & $69 \cdot 2(4 \cdot 6)$ & $61-76$ \\
\hline Smoking (pack years) & $69 \cdot 8(31 \cdot 6)$ & $20-165$ \\
\hline VC (\% predicted) & $85 \cdot 1(15 \cdot 9)$ & $54 \cdot 2-111 \cdot 7$ \\
\hline $\mathrm{FEV}_{1}(\mathrm{l})$ & $1.00(0.34)$ & $0.43-1.88$ \\
\hline $\mathrm{FEV}_{1}$ (\% predicted) & $40 \cdot 5(13 \cdot 7)$ & $19 \cdot 5-78 \cdot 0$ \\
\hline $\mathrm{FEV}_{1} / \mathrm{FVC}(\%)$ & $43.2(9 \cdot 6)$ & $21 \cdot 7-62 \cdot 4$ \\
\hline TLC (\% predicted)* & $126.9(21 \cdot 1)$ & $71 \cdot 3-134 \cdot 8$ \\
\hline RV/TLC (\%)* & $48 \cdot 0(10 \cdot 3)$ & $31 \cdot 1-71 \cdot 8$ \\
\hline TLCo (\% predicted) & $62 \cdot 7(13 \cdot 8)$ & $48 \cdot 0-110 \cdot 1$ \\
\hline $\mathrm{Kco}(\mathrm{mmol} / \mathrm{min} / 1 / \mathrm{kPa})$ & $1.11(0.35)$ & $0 \cdot 84-2 \cdot 38$ \\
\hline MVV (\% predicted) & $50 \cdot 8(17 \cdot 0)$ & $17 \cdot 7-56 \cdot 4$ \\
\hline Cst $(1 / \mathrm{kPa}) \dagger$ & $3.57(2.55)$ & $1 \cdot 02-12 \cdot 2$ \\
\hline $\operatorname{Raw}(\mathrm{kPa} / \mathrm{l} / \mathrm{s})^{*}$ & $0.55(0.13)$ & $0 \cdot 36-0.84$ \\
\hline $\mathrm{PaO}_{2}(\mathrm{kPa})$ & $10 \cdot 6(0.8)$ & $9 \cdot 0-12 \cdot 4$ \\
\hline $\mathrm{PaCO}_{2}(\mathrm{kPa})$ & $5 \cdot 6(0.4)$ & $4 \cdot 6-6$ \\
\hline
\end{tabular}

$\mathrm{VC}=$ vital capacity; $\mathrm{FEV}_{1}=$ forced expiratory volume in one second; FVC = forced vital capacity; TLC = total lung capacity; $\mathrm{RV}=$ residual volume; $\mathrm{TLCO}=$ carbon monoxide transfer factor $\mathrm{Kco}=$ carbon monoxide transfer coefficient; $\mathrm{MVV}=$ maximum voluntary ventilation; $\mathrm{Cst}=$ static compliance; $\mathrm{Raw}=$ airways resistance; $\mathrm{PaO}_{2}, \mathrm{PaCO}_{2}=$ arterial oxygen and carbon dioxide tensions.

* Not measured in two patients because of severe airways limitation.

$t$ Not measured in four patients because of servere airways limitation.

also carefully observed all of the spirometric measurements.

Spirometric parameters were assessed before and at 30, 60, 90, and 120 minutes after the inhalation. Before each spirometric measurement, pulse rate and blood pressure were measured after at least five minutes of rest. After obtaining the spirometric measurement at 90 minutes, symptom limited progressive cycle ergometry was performed. The patients were asked to note any side effects at each time period.

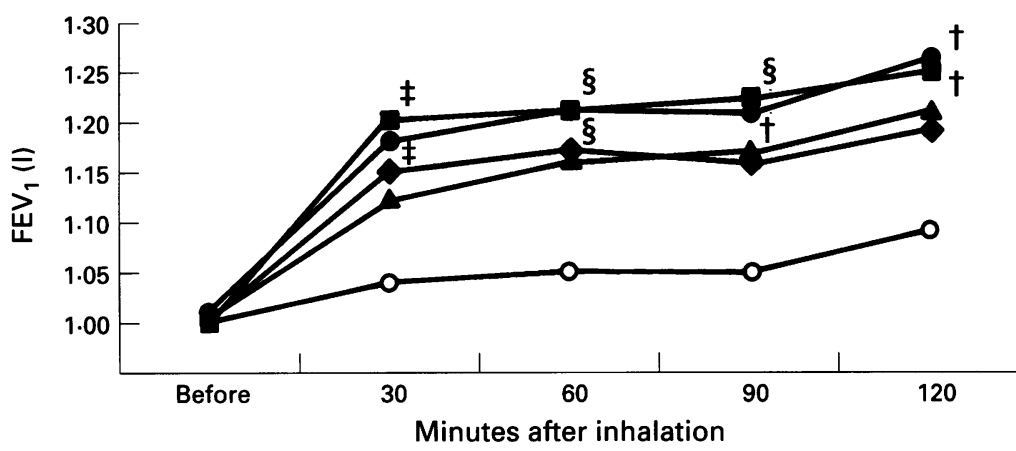

Figure 1 Time-response curve of forced expiratory volume in one second (FEV ) after inhalation of ipratropium bromide in doses of $40 \mu \mathrm{g}(\diamond), 80 \mu \mathrm{g}(\mathbf{\Delta}), 160 \mu \mathrm{g}(\mathrm{O})$, and $240 \mu g$ (). $F E V_{1}$ was significantly greater than in the placebo group (O) at all time points $(p<0.01)$. $† v 40 \mu g p<0.05 ; \ddagger v 80 \mu g p<0.05 ; \S v 40$ and $80 \mu g(p<0.05)$.

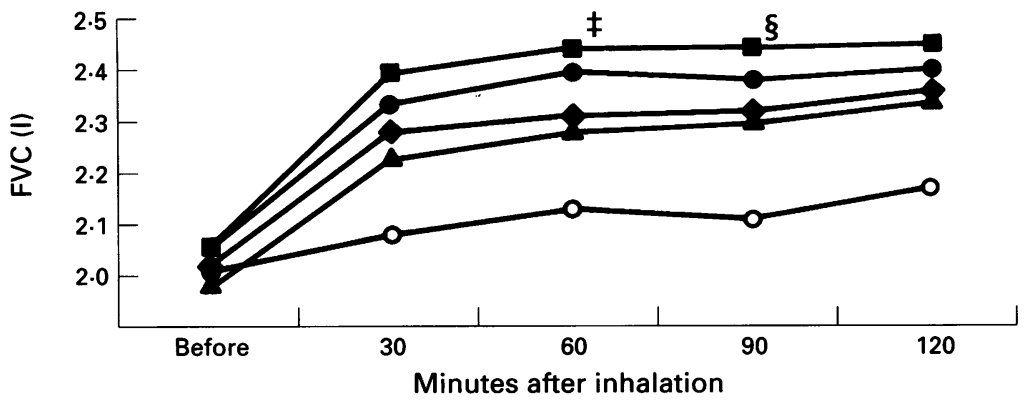

Figure 2 Time-response curve of forced vital capacity (FVC) value after inhalation of

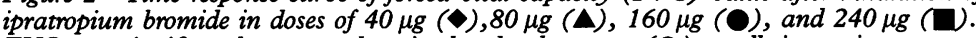
$F V C$ was significantly greater than in the placebo group $(O)$ at all time points $(p<0.01) . \ddagger v 80 \mu \mathrm{g}(p<0.05), \S v 40$ and $80 \mu g(p<0.05)$.
STATISTICAL ANALYSIS

All data are expressed as mean (SD). The significance of differences among values observed for the five treatment groups was determined by repeated measures analysis of variance. When a significant difference existed among groups, a two tailed paired $t$ test was used to identify where differences were significant. The relationship between two sets of data was analysed by Pearson's correlation coefficient. A $p$ value of less than 0.05 (two tailed) was considered significant for all tests.

\section{Results}

All 20 patients completed the entire study. On average, patients had spirometric evidence of moderate to severe airways obstruction and were mildly hypoxaemic when breathing room air (table 1).

There were no differences in $\mathrm{FEV}_{1}$ and FVC before inhalation in the treatment groups. At 90 minutes, treatment with 160 or $240 \mu \mathrm{g}$ ipratropium bromide produced greater improvements in $\mathrm{FEV}_{1}$ than 40 or $80 \mu \mathrm{g}$ ipratropium bromide (fig 1). No differences were observed between 160 and $240 \mu \mathrm{g}$ ipratropium bromide, or between 40 and $80 \mu \mathrm{g}$ ipratropium bromide. Nearly the same results were obtained for FVC values, but differences among the results at 40,80 , and $160 \mu \mathrm{g}$ ipratropium bromide did not reach significance (fig 2).

The mean Wmax in the second exercise test before entering the study was $85.0(20.6)$ watts, and no significant difference was found between this value and the placebo test during the study. This difference did not change significantly as the placebo test came later in the series of the study. Thus, the reproducibility of the exercise tests was considered to be good. Furthermore, because the order of the different drug doses was randomised, the effects of learning, training, or motivation were considered to be negligible.

At rest, no significant differences were observed in indices such as $\dot{\mathrm{VO}}_{2}, \dot{\mathrm{VE}}$, respiratory rate, or heart rate among the five treatment groups. At maximum exercise, treatment with 160 or $240 \mu \mathrm{g}$ ipratropium bromide produced significantly greater increases in $\mathrm{Wmax}$ $\dot{\mathrm{VO}}_{2} \mathrm{max}$, and $\mathrm{VEmax}$ than the placebo, whereas treatment with 40 or $80 \mu \mathrm{g}$ ipratropium bromide did not (table 2). The values of VEmax were obtained at approximately Wmax for each individual, and the ratio of VEmax/MVV was more than 1.0 in each group. No differences were observed in mean maximal heart rates, which were approximately $75 \%$ of the predicted values. Dyspnoea on the Borg scale at the end of exercise and $\mathrm{SaO}_{2}$ at maximum exercise were not different between any of the treatment groups.

To determine whether the observed improvement in exercise capacity was related to individual improvements in airways limitation we examined the relationship between the changes in $\mathrm{FEV}_{1}$ at 90 minutes and the changes in Wmax (fig 3). The data represent the differ- 
Table 2 Mean (SD) maximum exercise data for different dosage groups

\begin{tabular}{|c|c|c|c|c|c|}
\hline & Placebo & $40 \mu g$ & $80 \mu g$ & $160 \mu g$ & $240 \mu g$ \\
\hline Wmax (watts) & $86 \cdot 5(21 \cdot 0)$ & $88 \cdot 8(16 \cdot 7)$ & $89 \cdot 6(22.0)$ & $91 \cdot 7(19 \cdot 8) \ddagger$ & $90 \cdot 1(19.5) \dagger$ \\
\hline $\mathrm{VO}_{2} \max (\mathrm{ml} / \mathrm{min})$ & $865(184)$ & 879 (167) & $878(183)$ & $908(182) \ddagger$ & $904(159) t$ \\
\hline$\dot{\mathrm{V}} \mathrm{CO}_{2} \mathrm{max}(\mathrm{ml} / \mathrm{min})$ & $894(245)$ & $925(237)$ & $929(249)$ & $963(253) \ddagger$ & $950(230) \dagger$ \\
\hline VEmax $(1 / \min )$ & $37 \cdot 2(8 \cdot 7)$ & $39 \cdot 4(8 \cdot 5)$ & $39 \cdot 7(8 \cdot 3) \dagger$ & $41 \cdot 4(9 \cdot 8) \ddagger$ & $40 \cdot 5(9 \cdot 2) \ddagger$ \\
\hline VEmax/MVV (\%) & $103(27)$ & $108(25)$ & $109(24) t$ & $113(27) \ddagger$ & $111(26) \ddagger$ \\
\hline HR (beats/min) & $126(16)$ & $125(16)$ & $125(17)$ & $125(15)$ & $128(16)$ \\
\hline $\mathrm{SaO}_{2}(\%)$ & $94(4)$ & $93(4)$ & $94(4)$ & $93(4)$ & $94(4)$ \\
\hline Borg scale & $7 \cdot 5(1.4)$ & $7.6(1.4)$ & $7 \cdot 7(1.4)$ & $7 \cdot 7(1 \cdot 4)$ & $7 \cdot 5(1 \cdot 1)$ \\
\hline
\end{tabular}

$\mathrm{W} \max =$ maximum work rate; $\dot{\mathrm{Vo}}_{2} \mathrm{max}, \dot{\mathrm{V}} \mathrm{CO}_{2} \mathrm{max}=$ maximum oxygen and carbon dioxide consumption; $\mathrm{VEmax}=$ maximal vent ilation; $\mathrm{MVV}=$ maximum voluntary ventilation; $\mathrm{HR}=$ heart rate; $\mathrm{SaO}_{2}=$ arterial oxygen saturation .

$\dagger p<0.05$ versus placebo; $\neq p<0.01$ versus placebo.

ences in these two parameters between each of the $40,80,160$, and $240 \mu \mathrm{g}$ ipratropium bromide groups and the placebo treatment group in all of the 80 tests - that is, four tests for 20 patients. A significant correlation was found between the change in $\mathrm{FEV}_{1}$ and the change in $\mathrm{W} \max (r=0.45, \mathrm{p}<0.005)$.

Individual resting pulse rates and blood pressures did not differ between the active treatment group and the placebo group for any of the measurements. No patients complained of adverse symptoms.

\section{Discussion}

The results of this study show that the administration of $160 \mu \mathrm{g}$ or more ipratropium bromide with an MDI has a small but significant effect on exercise capacity in patients with COPD evaluated with progressive cycle ergometry, whereas doses below $80 \mu \mathrm{g}$ were less effective.

In the studies of Leitch et $a l^{6}$ Tobin et $a l^{7}$ and Brown et $a l^{8}$ the significant improvement in airway mechanics produced by inhaled anticholinergics did not result in a significant increase in maximum exercise capacity. One possible reason for this discrepancy with our results is that these workers used a smaller dose of inhaled anticholinergic agent, and thus maximal bronchodilation was not achieved. In our study at least $160 \mu \mathrm{g}$ ipratropium bromide, which is four times more than the recommended dose, was necessary for optimal

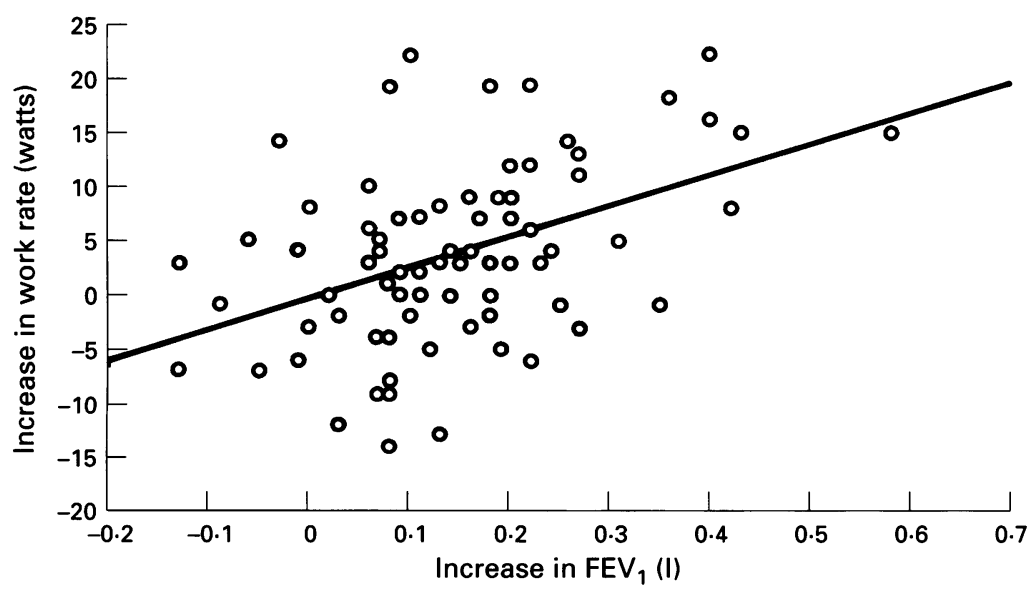

Figure 3 Correlation between the change in forced expiratory volume in one second (FEV $)$ before exercise (at 90 minutes) and the change in maximal work load. The data represent the differences in these two parameters between the ipratropium bromide and placebo treatment groups in all of the 80 tests. The correlation was significant $(r=0.45$, $p<0 \cdot 005$ ) bronchodilation. The currently recommended dose of ipratropium bromide produces less than maximal bronchodilation, and the dose can be doubled or tripled without notable side effects. ${ }^{15}$ According to bronchodilator responses following $40 \mu \mathrm{g}$ ipratropium bromide via an MDI and the results from a dose response study of nebulised ipratropium bromide, Gross et $a l^{16}$ speculated that the optimal dose of ipratropium bromide delivered by $\mathrm{MDI}$ in patients with stable COPD may be as much as four times the recommended dose. This speculation is consistent with our results. Ipratropium bromide does not have significant effects on the cardiovascular system - that is, heart rate or blood pressure ${ }^{1718}$ - even when given at eight times the currently recommended doses. ${ }^{19}$ Even in hypoxaemic patients this drug does not affect arterial blood gases. ${ }^{20}$ The present study also confirmed these findings.

Although non-asthmatic patients with COPD were included in the present study, $\mathrm{FEV}_{1}$ increased by an average of more than $15 \%$ after administration of the drugs under study. However, the mean absolute change in $\mathrm{FEV}_{1}$ was at most $250 \mathrm{ml}$, and this value is compatible with the changes reported in previous studies. ${ }^{3-5}$ Thus, our patients had partially reversible chronic airways limitation.

There was a significant correlation between the change in Wmax and the change in $\mathrm{FEV}_{1}$, but this correlation was too weak to conclude that the improvement in exercise tolerance depended solely on the reduction in airways limitation. The VE at Wmax was almost equal to VEmax in each individual, and the ratio of $\dot{V} E m a x / M V V$ was over 1.0 in every group. Although less convincing, this evidence would suggest that ventilatory mechanics were the limiting factor in the exercise tests. Carter et $a l^{21}$ reported that the equation $37 \cdot 5 \times \mathrm{FEV}_{1}$ was an accurate and robust predictor of VEmax when applied to patients with moderate to severe COPD $\left(\mathrm{FEV}_{1}\right.$ 0.56-1.61 1). Applying this rule to our data, the mean actual VEmax in each group did not reach the predicted value (about $90 \%$ of the predicted value in each group). This could imply that the patients in the present study still had some ventilatory reserve. Killian has shown that patients with obstructive airways disease generally stop exercising when the level of dyspnoea reaches 6 on the Borg scale, or when the perceived exertion of the working muscles reaches 7 on the same scale. ${ }^{22}$ The data from the present study show that all scores on the Borg scale were $7 \cdot 5$ or more at Wmax. This could suggest that 
dyspnoea and leg effort were the limiting factors rather than ventilatory mechanics. It is conceivable that ipratropium bromide at higher doses improves $\mathrm{FEV}_{1}$, thus improving dyspnoea, which allows for a higher Wmax.

Spence et al demonstrated that $200 \mu \mathrm{g}$ oxitropium bromide increased the six minute walking distance but not the duration of cycle exercise. ${ }^{23}$ They found that bicycle ergometry underestimates haemoglobin desaturation more than a corridor walking test, suggesting that self-paced exercise may be a more sensitive method, although the reason for this is not clear. In fact, the mean $\mathrm{SaO}_{2}$ was $97 \%$ at rest in the present study, and it did not drop below $93 \%$ at maximal exercise. Almost the same results were obtained in previous studies using cycle ergometry. ${ }^{2425}$ The possibility that a dose of ipratropium bromide of less than $160 \mu \mathrm{g}$ could improve exercise performance can be evaluated using the six minute walking distance test. Furthermore, a tightly fitting face mask can alter the breathing pattern ${ }^{26}$ and cycle exercise may also produce different data from a six minute walking test. Although there were only small changes in the exercise parameters in the present study, a small improvement in severely disabled patients with COPD may be of benefit. However, since data from cycle ergometer exercise tests are not directly relevant to usual exercise patterns ${ }^{27}$ it is difficult to evaluate how much improvement in exercise capacity would be experienced in daily life.

Hay et al reported that the increase in six minute walking distance seen with $200 \mu \mathrm{g}$ oxitropium bromide was unrelated to bronchodilation. ${ }^{9}$ These results suggest that anticholinergic therapy can improve dyspnoea and exercise tolerance in COPD, and that reversibility testing is not a good predictor of symptomatic benefits. The present study does not address the possibility that mechanisms other than bronchodilation could improve exercise tolerance. Anticholinergics might affect afferent vagal reflexes from the airways and lung, though their role in mediating the respiratory sensation of dyspnoea is not presently known. Theophylline may improve exercise tolerance by affecting respiratory muscle performance rather than by bronchodilation, ${ }^{2528}$ but anticholinergics are not considered to have such an effect. LoRusso reported that the maximum voluntary ventilation which requires inspiratory and expiratory effort was the single best predictor of $\mathrm{VO}_{2}$ in patients with COPD. ${ }^{29}$ Dillard et al demonstrated that factors other than ventilatory capacity also have a quantitative effect on $\mathrm{Vo}_{2} \mathrm{max}$, and that peak inspiratory pressure has an effect on maximal exercise capacity. ${ }^{30}$ Thus, inspiratory muscle function may be an important determinant of exercise performance.

We conclude that, although cycle ergometry is not directly relevant to exercise performed as daily activities, ipratropium bromide at doses of $160 \mu \mathrm{g}$ or more from an MDI with a spacer may be optimal for improving the maximal exercise capacity in patients with stable COPD.
This study was partly supported by a research grant from the Smoking Research Foundation of Japan. The authors thank Drs Naoharu Sugiura, Hideo Kita, and Kenzo Kawakami for performing the body plethysmography and Nippon Boehringer Ingelheim $\mathrm{Co}$. for providing the matching placebo of ipratropium bromide.

1 Filuk RB, Easton PA, Anthonisen NR. Responses to large doses of salbutamol and theophylline in patients with chronic obstructive pulmonary disease. Am Rev Respir Dis $1985 ; 132: 871-4$.

2 Lam A, Newhouse MT. Management of asthma and chronic airflow limitation. Are methylxanthines obsolete? Chest 1990;98:44-52.

3 Braun SR, McKenzie WN, Copeland C, Knight L, Ellersieck M. A comparison of the effect of ipratropium and albuterol in the treatment of chronic obstructive airways disease. Arch Intern Med 1989;149:544-7.

4 Baigelman W, Chodosh S. Bronchodilator action of the anticholinergic drug, ipratropium bromide (Sch 1000), as an aerosol in chronic bronchitis and asthma. Chest as an aerosol in

5 Tashkin DP, Ashutosh K, Bleecker ER, Britt EJ, Cugell DW, Cummiskey JM, et al. Comparison of the anticholinergic bronchodilator ipratropium bromide with metaproterenol in chronic obstructive pulmonary disease. A 90-day multi-center study. $A m$ f $M e d ~ 1986 ; 81$ (Suppl 5A):81-9.

6 Leitch AG, Hopkin JM, Ellis DA, Merchant S, McHardy GJR. The effect of aerosol ipratropium bromide and salbutamol on exercise tolerance in chronic bronchitis. Thorax 1978;33:711-3.

7 Tobin MJ, Hughes JA, Hutchison DCG. Effects of ipratropium bromide and fenoterol aerosols on exercise tolerance. Eur 7 Respir Dis 1984;65:441-6.

8 Brown SE, Prager RS, Shinto RA, Fischer CE, Stansbury DW, Light RW. Cardiopulmonary responses to exercise in chronic airflow obstruction: effects of inhaled atropine sulfate. Chest 1986;89:7-11.

9 Hay J, Stone P, Carter J, Church S, Eyre-Brook A, Pearson MG, et al. Bronchodilator reversibility, exercise performance and breathlessness in stable chronic obstructive pulmonary disease. Eur Respir 7 1992;5:659-64.

10 Teramoto S, Fukuchi Y, Orimo H. Effects of inhaled anticholinergic drug on dyspnea and gas exchange during exercise in patients with chronic obstructive pulmonary disease. Chest 1993;103:1774-82.

11 Medical Section of the American Lung Association. Standards for the diagnosis and care of patients with chronic obstructive pulmonary disease (COPD) and asthma. Am Rev Respir Dis 1987;136:225-44.

12 Medical Section of the American Lung Association. Standardization of spirometry - 1987 update. Am Rev Respir Dis 1987;136:1285-98.

13 Japan Society of Chest Diseases. The predicted values of pulmonary function testing in Japanese. FfTD 1993;31: appendix.

14 Tobin NJ, Jenouri G, Danta I, Kim C, Waston H, Sackner MA. Response to bronchodilator drug administration by a new reservoir aerosol delivery system and a review of other auxiliary delivery systems. Am Rev Respir Dis 1982;126:670-5.

15 Ferguson GT, Cherniack RM. Management of chronic obstructive pulmonary disease. $N$ Engl f Med 1993;328: 1017-22.

16 Gross NJ, Petty TL, Friedman M, Skorodin MS, Silvers GW, Donohue JF. Dose response to ipratropium as a nebulized solution in patients with chronic obstructive pulmonary disease. A three-center study. Am Rev Respir Dis $1989 ; 139: 1188-91$

17 Anderson WM. Haemodynamic and non-bronchial effects of ipratropium bromide. Am f Med 1986;81(Suppl 5A): $45-52$.

18 Chapman KR, Smith DL, Rebuck AS, Leenen FHH. Hemodynamic effects of ipratropium bromide, alone and combined with an inhaled beta ${ }_{2}$ agonist. Am Rev and combined with an in

19 Sacker MA, Friedman M, Silva G, Fernandez R. The pulmonary hemodynamic effects of aerosols of isoproterenol and ipratropium in normal subjects and patients with reversible airways obstruction. Am Rev Respir Dis 1977;116:1013-22.

20 Gross NJ, Bankwala Z. Effects of an anticholinergic bronchodilator on arterial blood gases of hypoxemic patients with chronic obstructive pulmonary disease. $A m$ Rev Respir Dis 1987;136:1091-4.

21 Carter $R$, Peavler $M$, Zinkgraf $S$, Williams J, Fields $S$. Predicting maximal exercise ventilation in patients with chronic

22 Killian KJ, Leblanc P, Martin DH, Summers E, Jones NL, Campbell EJM. Exercise capacity and ventilatory, circulatory, and symptom limitation in patients with chronic airflow limitation. Am Rev Respir Dis 1992;146: 935-40.

23 Spence DPS, Hay JG, Carter J, Pearson MG, Calverley PMA. Oxygen desaturation and breathlessness during corridor walking in chronic obstructive pulmonary disease: effect of oxitropium bromide. Thorax 1993;48: 1145-50.

24 Carter R, Nicotra B, Blevins W, Holiday D. Altered 
exercise gas exchange and cardiac function in patients with mild chronic obstructive pulmonary disease. Chest 1993;103:745-50.

25 Fink G, Kaye C, Sulkes J, Gabbay U, Spitzer SA. Effect of theophylline on exercise performance in patients with severe chronic obstructive pulmonary disease. Thorax 1994;49:332-4.

26 Gilbert R, Auchincloss JH Jr, Brodsky J, Boden W. Changes in tidal volume, frequency, and ventilation induced by their measurement. $₹$ Appl Physiol 1972;33:252-4.

27 Minh VD, Lee HM, Dolan GF, Light RW, Bell J, Vasquez P. Hypoxemia during exercise in patients with chronic obstructive pulmonary disease. Am Rev Respir Dis 1979; 120:787-94.

28 Murciano D, Auclair MH, Pariente R, Aubier M. A randomized, controlled trial of theophylline in patients with severe chronic obstructive pulmonary disease. $N E n g l f M e d$ 1989;320:1521-5.

29 LoRusso TJ, Belman MJ, Elashoff JD, Koerner SK. Prediction of maximal exercise capacity in obstructive and rediction of maximal exercise capacity in obstructive and

30 Dillard TA, Piantadosi S, Rajagopal KR. Determinants of maximum exercise capacity in patients with chronic airflow obstruction. Chest 1989;96:267-71. 